\title{
Model of Integrated Quality and Safety Management System for Collagen Production
}

\author{
Assemay T. Kazhymurat, Raushangul U. Uazhanova, Ulbala O. Tungyshbayeva, Dinara A. Tlevlesova \\ Almaty Technological University, Republic of Kazakhstan, 050012, Almaty, Tole bi Street, 100,
}

\begin{abstract}
The article presents results of the researches on creation of integrated quality management system for collagen enterprise reflecting branch specifics in a basis of the international ISO standards of series 9001, principles of HACCP and FMEA. Theoretical and practical aspects of construction and development of systems of QMS, HACCP and FMEA are analysed and the technique of creation of the integrated safety quality management system (ISQMS) of the LPP «Antigen» is offered. Degrees of compatibility of the international ISO 9001:2015 standard (ST RK ISO 9001-2016) and the principles of HACCP (ST RK 1179-2003), ST RK IEC 60812-2005 are defined. The conceptual model of the ISQMS is offered. Areas of integration of FMEA, HACCP and QMS systems are also established and the additive model of creation of the ISQMS is chosen. The network of the processes of the ISQMS of the LPP «Antigen» on the basis of the carried-out process's integration is created.
\end{abstract}

Keywords: Integrated system, Failure Modes and Effect Analysis (FMEA), Hazard Analysis Critical Control Point (HACCP) collagen hydrolyzate, ISO.

\section{INTRODUCTION}

In connection with Russia's accession to the WTO and the organization of the Customs Union, significant changes have occurred in the legislative and regulatory documents relating to issues of quality and safety of food products. According to the Technical Regulation of the Customs Union 021/2011 "On the safety of food products", "in the implementation of production processes (manufacturing) of food products related to the safety requirements of such products, the manufacturer must develop, implement and maintain procedures based on the principles of HACCP". Thus, the development and implementation of security management systems becomes mandatory for food enterprises, including candy stores. Without a certificate of conformity for a food safety management system, an enterprise will not be able to receive a certificate (declaration) of conformity for its products in the future [1].

The entry of the Republic of Kazakhstan into the Customs Union led to the reform of the Kazakhstan economy and its transition to a market level, as well as to the need to apply international rules [2].

Integration into the global economic community creates certain risks for the domestic food industry, requires the adoption of comprehensive measures to increase competitiveness and to implement in practice international standards in the field of food safety. Currently, not only the development and implementation of food safety management systems is promising, but also the development and implementation of integrated management systems (IMS). The activities of a modern enterprise are regulated by international standards. Russia, being in the world community, cannot reject the need to create IMS according to the requirements of various international standards, such as ISO 9001: 2011, ISO 22000: 2005, ISO 14001, OHSAS 18000, ISO 27000, ISO 26000, etc [3].

Modern Kazakhstan industrial enterprises operate in conditions of great competition. In this situation, in order to ensure stable operation and development, enterprises need to produce high-quality and safe products in order to fully satisfy consumer preferences. In this regard, the development and use of such quality management systems that guarantee the necessary and stable quality and safety of products for the consumer is becoming increasingly important.

In modern market conditions, the stable and successful operation of an enterprise is determined by a number of factors, the main of which is the ability to meet consumer needs with high-quality and safe products. The rational use of the full potential of modern management, combining world experience, allows us to maintain and strengthen market positions, relying mainly on our own resources. A necessary condition for the successful integration of Kazakhstan enterprises in the international economic space is the active use of world experience and the latest scientific developments [4].

Modern trends in the development of the food industry, and in particular the production of meat products, are associated with continuous improvement of production technologies and effective policies in the field of ensuring the quality and safety of products that require the use of integrated approaches to risk management. By implementing standards for product quality management systems, enterprises can achieve recognition only on certain aspects of their activities, while at the same time creating inconsistencies in the management of various ektami within the enterprise. In this regard, the solution to this problem is to integrate disparate measures into a single system of ongoing activities at all stages of the product life cycle. Currently, the creation of integrated systems for managing the quality and safety of products at meat processing enterprises is in the initial stage, which is caused by the lack of a single formalized approach, as well as 
the lack of guidelines for their implementation [5].

Taking into account the requirements of the above standards and business development strategies, it is possible to build a modern integrated enterprise management system focused on the concept of sustainable development. The aim of this work is the development and implementation of an integrated quality and food safety management system for compliance with the requirements of ISO 9001-2015, HACCP system and FMEA at LPP «Antigen» .

The disadvantages of independently existing systems include the following aspects: a) poor business focus; b) a fragmented approach to the management of production risks; c) the presence of contradictions between the systems; d) duplication of work and bureaucracy; e) not entirely effective and ineffective internal and external audits.

Given the above, the need to create an integrated quality system and product safety, based on the standards of ISO 9001-2015, HACCP system and FMEA, is relevant. The introduction of an integrated system will allow manufacturers of collagen products to link safety requirements and product quality, manage them and meet customer requirements.

\section{OBJECTS AND METHODS}

As the base enterprise for the fulfillment of the purpose and objectives of the thesis, the scientific production enterprise "Antigen", the Almaty region, in the village of Abay was chosen.

Theoretical foundations of modeling methods for an integrated collagen production safety management system. IDEF0 Methodology.

\section{DEF0 Methodology}

Currently, there are a lot of software tools on the market with which you can build functional, informational, cost and simulation models of processes, enterprise management systems. For example, BPwin, ERwin, Sign / IDEF, Easy ABC, Design / CPN, S-Designor, CASE-Lalistic, Designer / 2000, ReThink, ABC Flowcharter, Oracle * Case, Visible Analyst Workbench, EasyCASE, Silverrun, Westmount I CASE, PRO-IV, Select Yourdon, PDM STEP Suite, software products of the ARIS series, etc [6].

The most widely used business process description methodology is the US IDEF0 standard. The IDEF0 approach was developed based on the SADT structural analysis and design methodology..

The IDEF0 methodology provides the analyst with excellent opportunities to describe the business of the enterprise at the top level with an emphasis on process management. Notation allows reflecting feedbacks of various types in the process model: according to information, on management, the movement of material resources. Well-thought-out mechanisms for decomposing a process model in IDEF0 greatly simplify the work of an analyst. It should be noted that the models in the IDEF0 notation are designed to describe the business at the top level. The main advantage is the ability to describe enterprise process management.

The main object of the process diagram in IDEF0 notation is the Activity object. Graphically, it is a quadrangle depicting the functions performed in an organization (Figure 1). Recall that each function (procedure, work) can be considered as some process. At the top level, each process can be considered as a "black box" that converts incoming resources into outgoing ones. This definition is the same as the definition in ISO 9000.

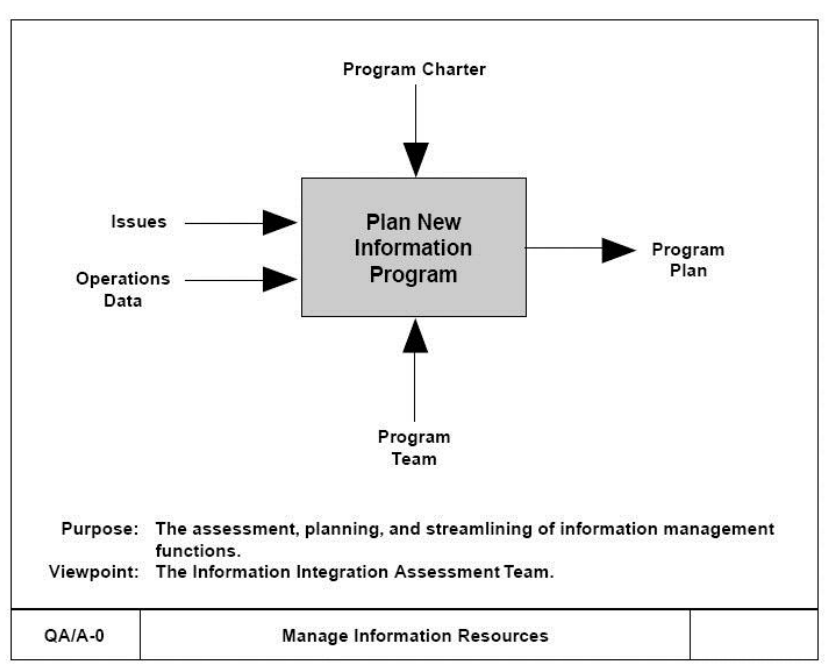

Figure 1: Formation of a business process model

Here are the main advantages and disadvantages of the IDEF0 methodology.

Benefits:

- The completeness of the description of the business process (management, information and material flows, feedbacks);

- Complexity during decomposition (migration and tunnel decomposition of arrows);

- Ability to aggregate and drill down data and information flows (separation and merging of arrows);

- The presence of stringent requirements of the methodology, ensuring the receipt of process models of a standard form;

- Ease of documenting processes;

- Conformity of the approach to the description of processes in IDEF0 ISO 9000.

Disadvantages:

- The complexity of perception (a large number of arrows);

- A large number of levels of decomposition;

- The difficulty of linking several processes represented in different models of the same enterprise.

The most important characteristic of IDEF0 is the completeness of the description of the business process, which is achieved through the availability of tools that display 
International Journal of Engineering Research and Technology. ISSN 0974-3154, Volume 13, Number 11 (2020), pp. 3675-3684

(C) International Research Publication House. https://dx.doi.org/10.37624/IJERT/13.11.2020.3675-3684

control actions, feedback on management and information. Such a mechanism ensures the coherence of the created diagrams among themselves. In addition, it makes the process model intuitive.

\section{RESULTS AND DISCUSSION}

Establishing the ideological proximity of approaches to creating an integrated quality and safety system based on ISO 9001: 2015, HACCP and FMEA systems

The initial stage of designing an integrated safety and quality system in the production of collagen is a comparative analysis of the requirements of the standards being implemented, for this purpose, to assess the possibility of integrating the HACCP system into the existing quality management system in the production of collagen, we examined the structures of standards ST RK ISO9001: 2016, ST RK 1179 - 2003 (HACCP system) and the FMEA system was considered for determining control critical points. The main advantage of ST RK ISO 9001: 2016 standard is that it is focused on consumers and is aimed at systemically ensuring the quality of products at all stages of its life cycle, since it is impossible to improve the quality level of products through the implementation of separate, isolated from each other measures.

As a result of the foregoing and based on a comparison of the requirements of these standards, the following elements are proposed, presented in table 1 . The first column of the table provides a complete list of the elements, requirements of the integrated quality and safety management system, the following columns introduce the requirements of the QMS, HACCP and FMEA standards that correspond to the elements integrated quality and safety management system.

Table 1: Matrix of requirements for elements of an integrated quality and safety management system

\begin{tabular}{|c|c|c|c|}
\hline \multirow[t]{2}{*}{ Requirements for an Integrated Quality and Safety Management System } & \multicolumn{3}{|c|}{$\begin{array}{l}\text { Integrated Requirements } \\
\text { standard }\end{array}$} \\
\hline & ISO 9001: 2015 & ST RK 1179 - 2003 & FMEA \\
\hline 1 & 2 & 3 & 4 \\
\hline 1 area of use & p.1 & p.1 & \\
\hline 2. Terms and definitions & p. 3 & p. 2 & \\
\hline \multicolumn{4}{|l|}{ 4. Integrated quality and safety management system } \\
\hline \multirow[t]{9}{*}{ 4.1 General - Organization Environment } & p. 4 & p.4.2 & p.5.2.1 \\
\hline & & p.4.2.1 & p.5.2.2 \\
\hline & & p.4.2.2 & p.5.2.2.2 \\
\hline & & p.4.2.2.1 & p.5.2.2.5 \\
\hline & & p.4.2.3 & \\
\hline & & p.4.3.1 & p.5.2.3 \\
\hline & & p.4.3.2 & p.5.2.5 \\
\hline & & & p.5.2.6 \\
\hline & & p.4.4 & p.5.3.1 \\
\hline 4.2 Documented information & p. 7.5 & p. 4.9 & \\
\hline \multicolumn{4}{|l|}{ 5. Leadership } \\
\hline $\begin{array}{l}\text { 5.1 Leadership and Commitment } \\
\text { 5.2 Customer orientation }\end{array}$ & $\begin{array}{l}\text { p. } 5.1 \\
\text { p. } 5.1 .2\end{array}$ & $\begin{array}{l}\text { p. } 4.1 .1 \\
-\end{array}$ & p. 5 \\
\hline 5.3 Quality and safety policy & p. 5.2 & p. 4.1 .2 & p.5.1 \\
\hline 5.4 Planning an integrated quality and safety management system & p.6 & p.4.1.2 & p.5.3 \\
\hline 5.4.1 Quality and safety objectives & p. 6.2 & p. 4.1 .2 & p.5.4.2 \\
\hline $\begin{array}{l}\text { 5.4.2 Planning for the creation, maintenance and improvement of } \\
\text { ISMQS }\end{array}$ & p. 5.4 .2 & up. $5.3 ; 8.5 .2$ & p.5.4.1 \\
\hline 5.5 Responsibility, authority and exchange of information & & & \\
\hline
\end{tabular}


International Journal of Engineering Research and Technology. ISSN 0974-3154, Volume 13, Number 11 (2020), pp. $3675-3684$

(C) International Research Publication House. https://dx.doi.org/10.37624/IJERT/13.11.2020.3675-3684

\begin{tabular}{|c|c|c|c|}
\hline 5.5.1 Responsibility and authority & p.5.5.1 & p.5.4 & p.5.5.1 \\
\hline 5.5.2 Management Representative & p. 5.5 .2 & p.5.5 & p.5.5.2 \\
\hline 5.5.3 Internal communication & p. 5.5 .3 & p. 5.6 .2 & \\
\hline 5.5.4 External communication & p. 7.2 .3 & p.5.6.1 & \\
\hline \multicolumn{4}{|l|}{ 5.6 Management review } \\
\hline 5.6.1 General & p. 5.6 .1 & p. 5.8.1 & \\
\hline 5.6.2 Input for analysis & p. 5.6 .2 & p. 5.8 .2 & \\
\hline 5.6.3 Output for analysis & p.5.6.3 & p. 5.8 .3 & \\
\hline \multicolumn{4}{|l|}{ 6. Resource Management } \\
\hline 6.1 Resource provision & p. 6.1 & p. 6.1 & \\
\hline \multicolumn{4}{|l|}{6.2 Human resources } \\
\hline 6.2.1 General & p. 6.2 .1 & p. 6.2 .1 & \\
\hline 6.2.2 Competence, training and awareness & p. 6.2 .2 & p. 6.2 .2 & \\
\hline 6.3 Infrastructure & p. 6.3 & up. $6.3 ; 7.2 ; 7.5$ & \\
\hline 6.4 Production environment & p.6.4 & up. $6.4 ; 7.2 ; 7.5$ & \\
\hline \multicolumn{4}{|c|}{ 7. Processes of an integrated quality and safety management system } \\
\hline 7.1 Planning of ISMQS processes & p. 7.1 & p. 7.1 & \\
\hline \multicolumn{4}{|c|}{ 7. Processes of an integrated quality and safety management system } \\
\hline 7.1 Planning of ISMQS processes & p. 7.1 & p. 7.1 & \\
\hline \multicolumn{4}{|l|}{ 7.2 Consumer related processes } \\
\hline 7.2.1 Definition of product related requirements & p. 7.2.1 & & \\
\hline 7.2.2 Analysis of product-related requirements & p. 7.2 .2 & & 7.2 .3 \\
\hline \multicolumn{4}{|l|}{ 7.3 Design and Development } \\
\hline 7.3.1 Design and development planning & p. 7.3.1 & & \\
\hline 7.3.2 Input for design and development & p.7.3.2 & p. 7.3 & \\
\hline 7.3.3 Design and development output & p. 7.3 .3 & p. 7.6 & \\
\hline 7.3.4 Design and development analysis & p. 7.3 .4 & p. 7.4 & \\
\hline 7.3.5 Verification of design and development & p. 7.3.5 & p. 7.8 & \\
\hline 7.3.6 Validation of design and development & p. 7.3.6 & p. 8.2 & \\
\hline 7.3.7 Project and development change management & p.7.3.7 & p. 7.7 & p.7.3.7 \\
\hline \multicolumn{4}{|l|}{ 7.4 Purchasing } \\
\hline 7.4.1 Procurement Process & p. 7.4.1 & & \\
\hline 7.4.2 Purchasing Information & p.7.4.2 & & \\
\hline 7.4.3 Verification of purchased products & p.7.4.3 & p.. 7.2 & p.7.2.1 \\
\hline \multicolumn{4}{|l|}{ 7.5 Production and service } \\
\hline 7.5.1 Production and service management & p. 7.5.1 & & \\
\hline 7.5.2 Validation of production and service processes & p.7.5.2 & p. 8.2 & 5.5.3 \\
\hline
\end{tabular}


International Journal of Engineering Research and Technology. ISSN 0974-3154, Volume 13, Number 11 (2020), pp. 3675-3684

(C) International Research Publication House. https://dx.doi.org/10.37624/IJERT/13.11.2020.3675-3684

\begin{tabular}{|c|c|c|c|}
\hline 7.5.3 Identification and traceability & p.7.5.3 & p.7.9 & \\
\hline 7.5.4 Собственность потребителей & p.7.5.4 & & \\
\hline 7.5.5 Сохранение соответствия продукции & p.7.5.5 & p.7.2 & \\
\hline 7.6 Management of equipment for monitoring and measurement & p.7.6 & p.8.3 & \\
\hline \multicolumn{4}{|l|}{$\begin{array}{l}\text { 8. Measurement, analysis and improvement of the integrated quality and } \\
\text { safety management system }\end{array}$} \\
\hline 8.1 General & p.8.1 & p.8.1 & \\
\hline \multicolumn{4}{|l|}{ 8.2 Monitoring and measurement } \\
\hline 8.2.1 Customer Satisfaction & p.8.2.1 & & \\
\hline 8.2.2 Internal audits & p.8.2.2 & p.8.4.1 & \\
\hline 8.2.3 Monitoring and measurement of processes & p.8.2.3 & up.7.6.4, 8.4.2 & \\
\hline 8.2.4 Product Monitoring and Measurement & p.8.2.4 & & \\
\hline 8.3 Management of nonconforming products & p.8.3 & up. $7.10 .3-7.10 .4$ & \\
\hline 8.4 Data Analysis & p.8.4 & p.8.4.3 & \\
\hline $\begin{array}{l}\text { 8.5 Improvement } \\
\text { 8.5.1 Continuous Improvement } \\
\text { 8.5.2 Corrective action } \\
\text { 8.5.3 Preventive actions }\end{array}$ & $\begin{array}{l}\text { p.8.5.1 } \\
\text { p.8.5.2 п. 8.5.3 }\end{array}$ & $\begin{array}{l}\text { p. } 8.5 .1 \text { up. } 7.10 .1- \\
7.10 .2 \text { p. } 5.7\end{array}$ & \\
\hline
\end{tabular}

\subsection{Development of a draft model of an integrated safety system and quality of collagen hydrolysate}

The basic idea of building an integrated management system implies that the organization will operate one management system, and not three or four independent systems. In practice, the main way to integrate management systems is to build some basic system, and complement it with more specific processes from the corresponding subject areas. As a rule, the standard ISO 9001 is used as the basis, as the most comprehensive and covering most of the management system. In addition, an approach based on risk assessment of the new edition of ISO 9001 allows for closer integration and simpler implementation of individual standards in a single integral system.

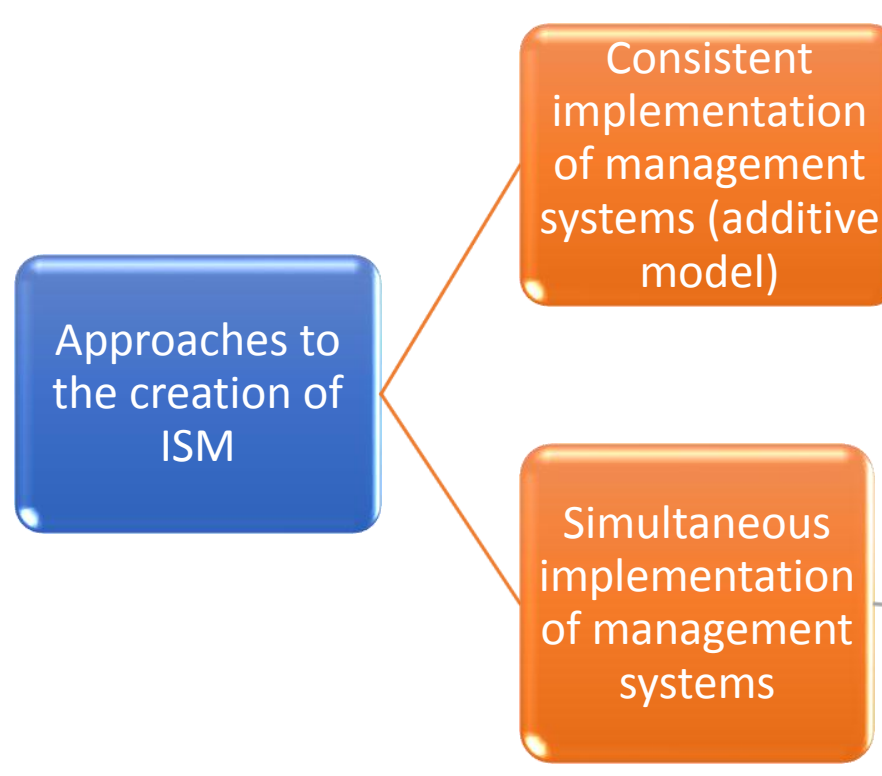

Consistent implementation

of two or more management

systems, starting with ISO 9001

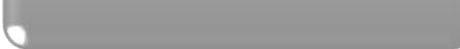

Development and

implementation of QMS in

accordance with ISO 9001 and

subsequent parallel

implementation of several

more systems simultaneously

Simultaneous

implementation of the

requirements of several

management systems, one

of which in the vast majority of cases is the QMS 
1) Creating additive integrated models:

This approach is based on the merger of private management systems, while the existing management system or one of the private implemented systems can be selected for the basic management system. The advantage of the approach is that the experience gained in the development, implementation and improvement of the current system is used to set and achieve goals that reflect the characteristics of the external environment of a different nature; Creating simultaneously integrated models:

With this approach, all management systems are simultaneously combined to build a universal enterprise management system. It is assumed that this method can be implemented when the organization does not have a developed management system.

The HACCP system, as a component of the overall quality management system, is developed separately (unique) for each company, and must meet the needs that are internal and external to the organization. It is important to distinguish between the quality of concepts and food safety (with HACCP, primarily to meet security needs), when the QMS used as a component of the quality management system is. HACCP has 4 levels in which it should be integrated into companies: process, inspection / regulation, integration system and cultural integration.
Culture

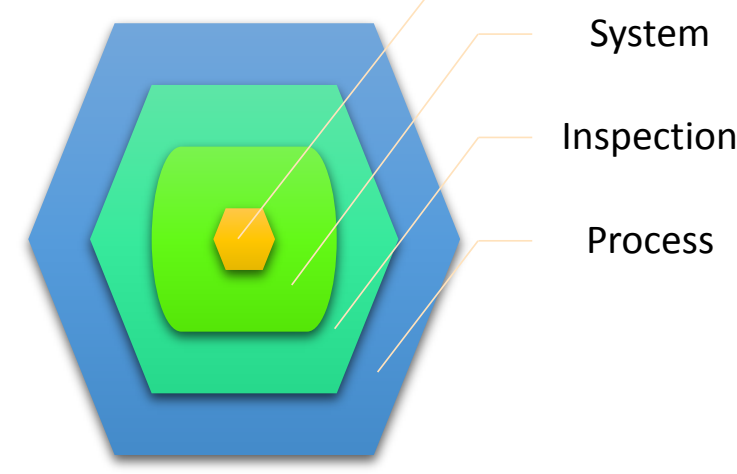

Figure 1: Four levels of HACCP integration in a company

One of the main tasks of designing an integrated management system is the stage of identification and integration of the QMS, HACCP and FMEA processes, followed by the establishment of the sequence and interactions of the identified processes When decomposing processes and integrating them into a common network of enterprise processes, it is very important to ensure the efficient use of all types of resources and the integrity of the perception of the management system by management and personnel, as well as to avoid duplication of the components of the integrated safety and quality system. For this, it is necessary to determine and take into account the specific requirements of the standards ST RK ISO 9001: 2016, ST RK 1179 - 2003 (HACCP system) and the FMEA system, which must be performed for this process, operating within the framework of an integrated quality safety system (Figure 2).

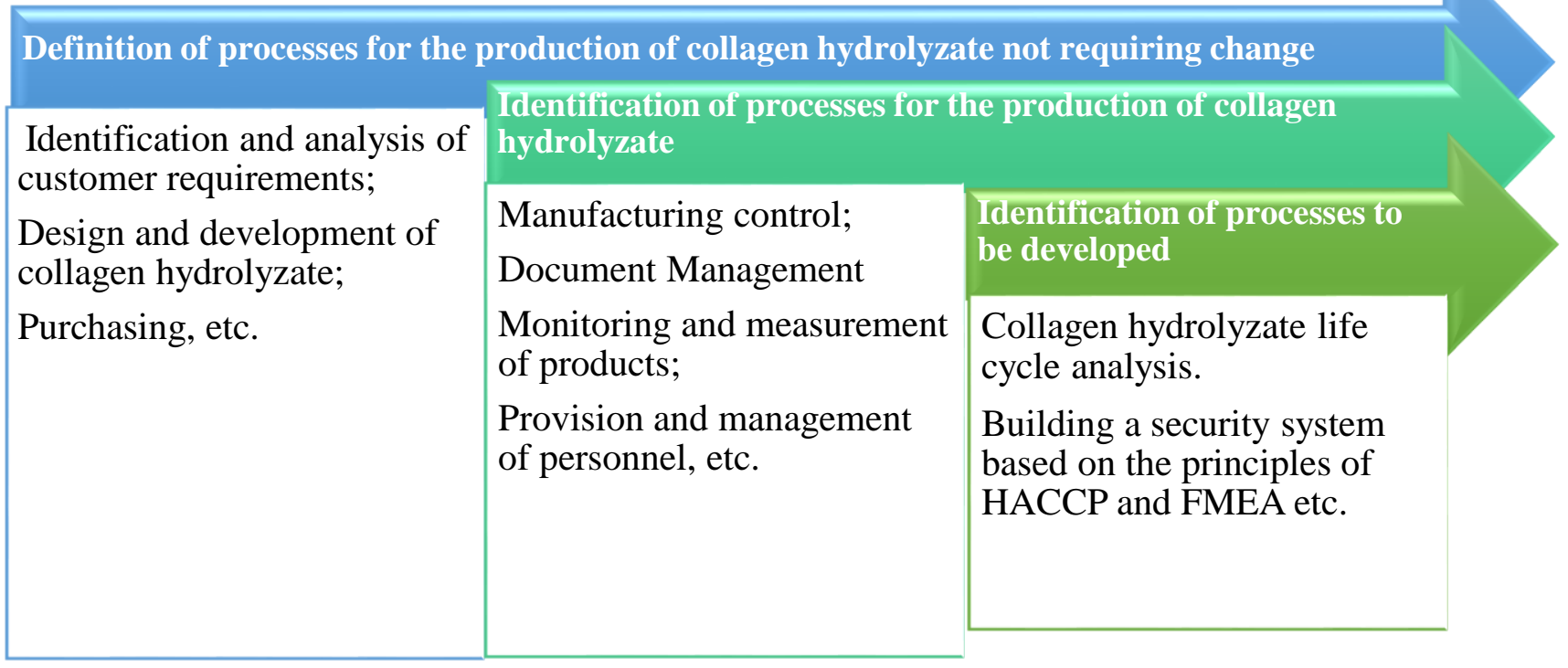

Figure 2: Identification and integration of the QMS, HACCP and FMEA processes, followed by the establishment of the sequence and interactions of the identified processes 
For the processes to be reviewed, a phased decomposition of the processes operating within the QMS was carried out taking into account the specific requirements of the HACCP system and FMEA, which must be taken into account for the full functioning of the integration of the safety and quality system.

The HACCP system establishes more stringent requirements for the production of products, which must be taken into account when decomposing the "Production Management" process into integrating safety and quality systems. At the same time, the following sub-processes "Validation", "Prevention of cross-contamination" and "Packaging" should be added to this process, the presence of which will ensure compliance with the specific requirements of ST RK 1179 2003 (HACCP system) to the process "Production management"

\subsection{Implementation of the HACCP system for collagen production.}

Development of elements of an integrated quality and safety management system

The PAS 94 Guide for Standards Developers provides a framework for the general requirements established in management system standards.
Key requirements are classified by the following points:

a) politics;

b) planning;

c) implementation and production;

g) improvement;

e) management analysis.

Each management system standard includes its own specific requirements; however, these six points will be present in all standards and can be taken as the basis for integration.

The standards ST RK ISO 9001: 2016, ST RK 1179 - 2003 (HACCP system) and the FMEA system are characterized by methodological and ideological proximity. Even a superficial familiarization with standards based on an analysis of their structures allows us to verify the ideological and methodological proximity of these standards. The integration of these management systems into an integrated system is facilitated by the proximity of the composition and structure of standardization objects, the compatibility of a number of elements and their requirements. The universality of the methodology and requirements of the ISO 9001 standard allows integration of the standard ST RK 1179-2003 into the enterprise management system without any difficulties. A schematic representation of the process elements is shown in Figure 3

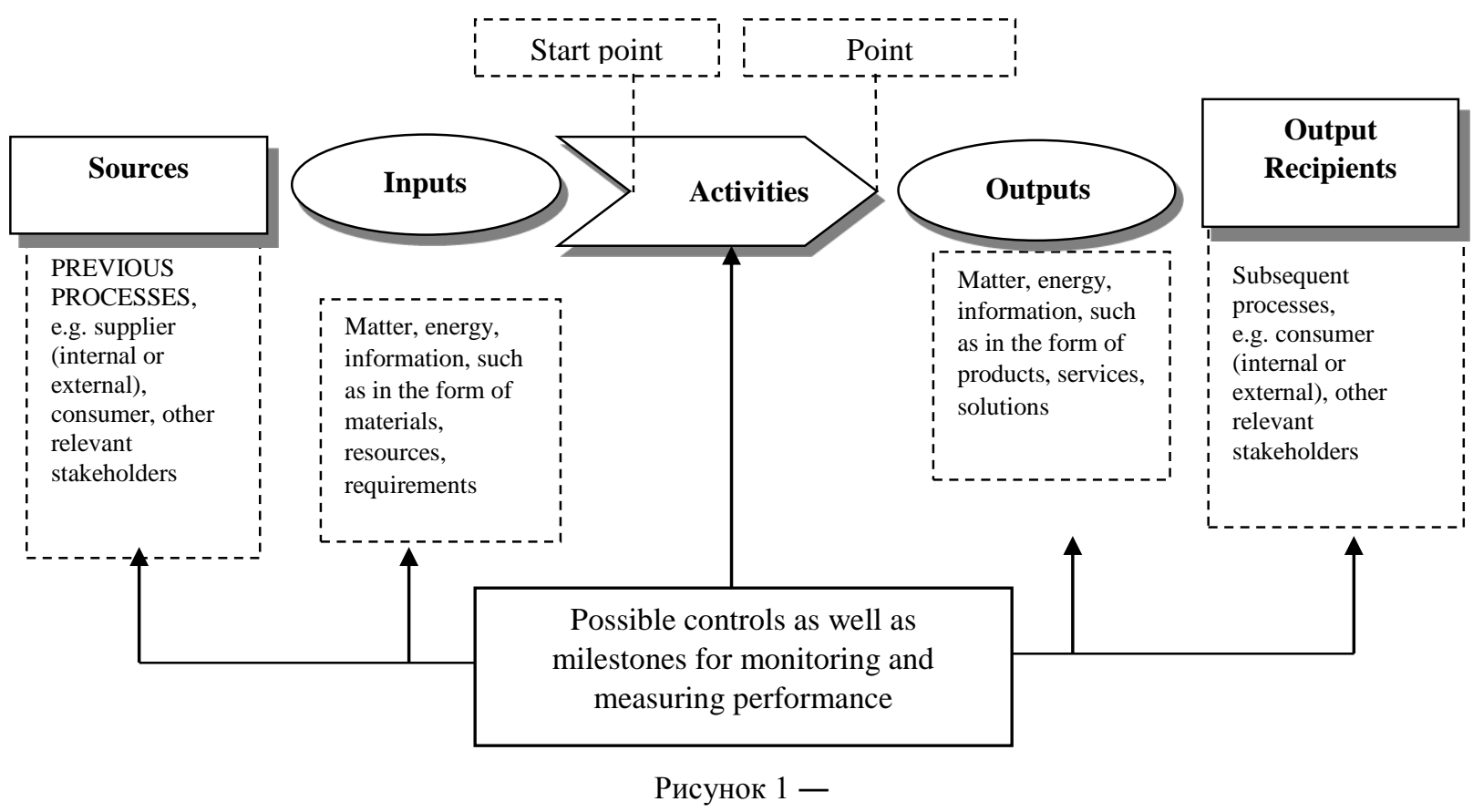

Figure 3: Schematic representation of the process elements

The understanding of the organization and its environment of the ISO 9001: 2015 standard is as follows: "The organization must determine the external and internal factors related to its intentions and strategic direction and affecting its ability to achieve the intended result (s) of its quality management system.". As applied to the integrated quality and production safety system, this requirement can be rephrased as follows:
"The organization must determine external and internal factors related to its intentions and strategic direction and affecting its ability to achieve the intended result (s) of its quality management system and food safety, constantly improve its effectiveness in accordance with the requirements of ISO 9001: 2015, HACCP and FMEA systems. " 
The formation of a model of an integrated quality and safety management system requires a clear establishment of its structure (elements) by organically combining the requirements laid down in these standards.

To develop elements of an integrated quality and safety management system, it is necessary to clearly define the areas of integration of these standards. We have established the areas of integration presented in Figure 4.

As a result, 14 areas of integration were identified. Figure 4 shows that using the principle of combining for integration, the requirements of the ISO 9001 standard will be supplemented with the corresponding requirements of the HACCP system, and those requirements that are specific to these standards will be fully included in the elements of the integrated system.

The integrated model will be based on the principles, requirements and approaches laid down in ISO 9001 as the most advanced and universal [7].

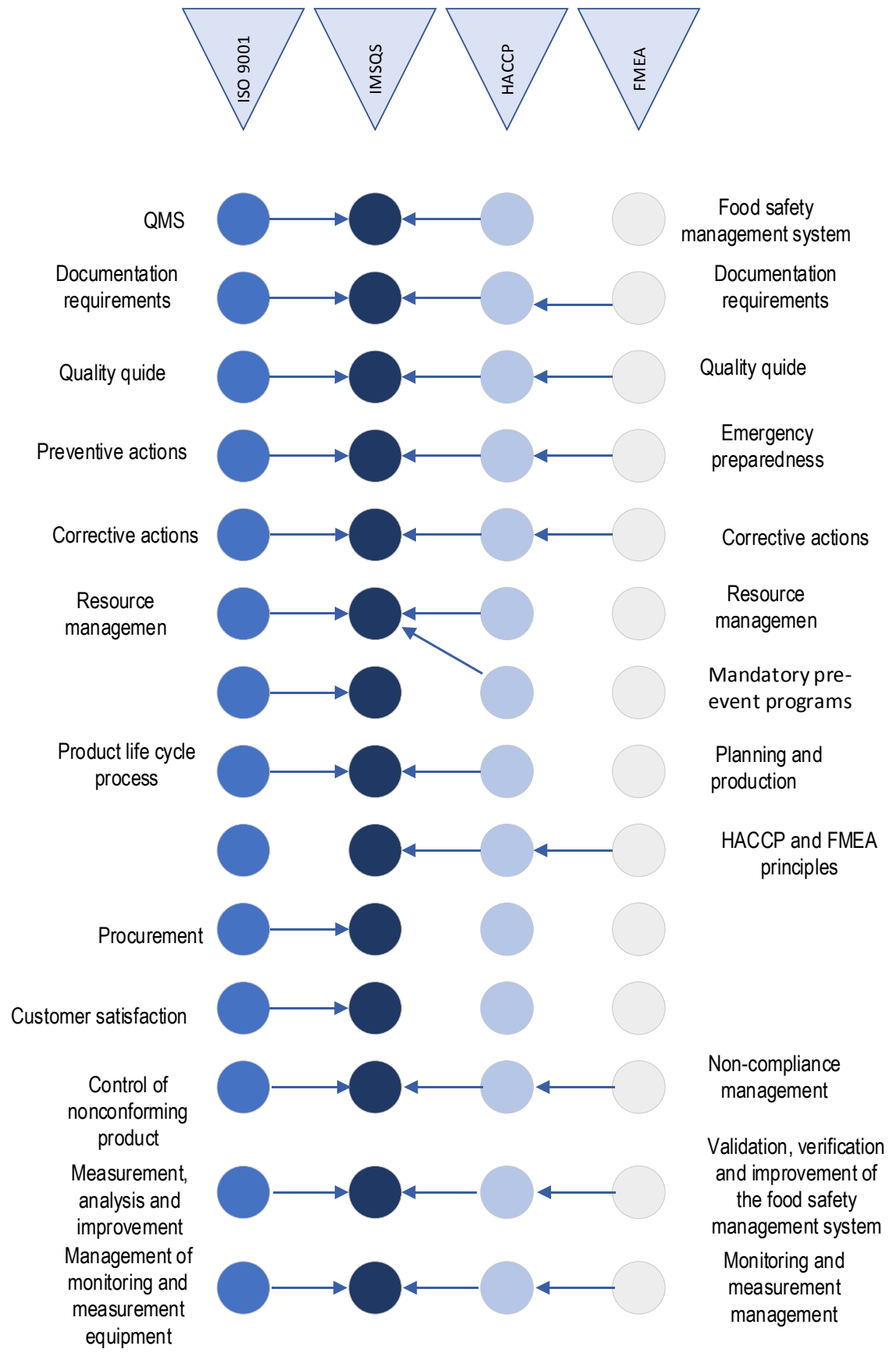

- HACCP system requirements; - requirements of the standard ISO 9001: 2015; - FMEA system requirements

Figure 4: The integration of the ISO 9001, HACCP system and the system FMEA 
Based on the formulated requirements (elements), a model of an integrated quality and safety management system was built based on a process approach that illustrates the relationships between processes (Figure 5).

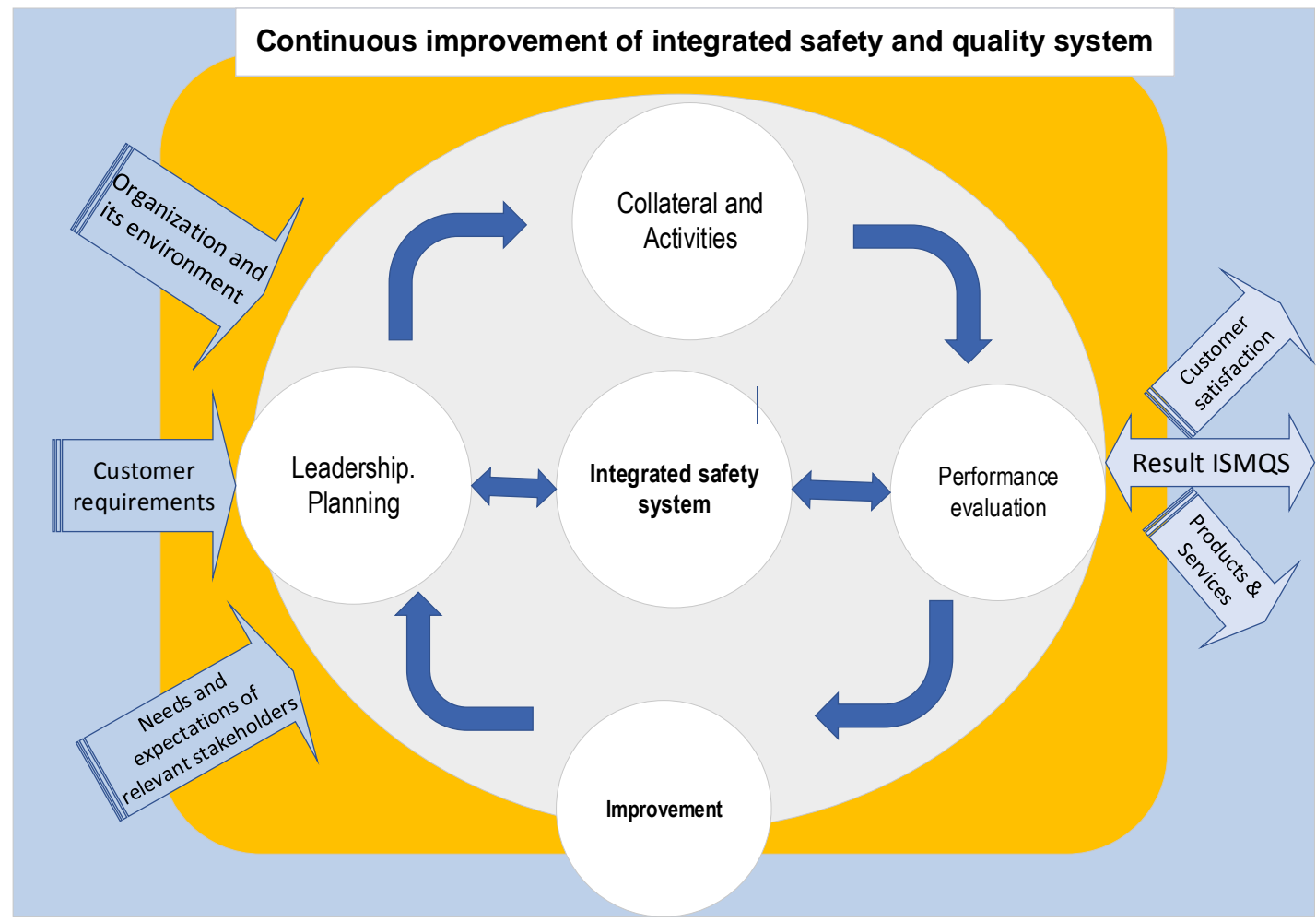

Figure 5: Model of an integrated quality and safety management system

PDCA is applied to enterprise IMS processes. Based on the foregoing, a model has been developed for an integrated safety and quality system for collagen hydrolyzate that meets the requirements of three standards: ST RK ISO 9001: 2016, ST RK 1179 - 2003 (HACCP system) and the FMEA system. The scheme of interaction of IMS processes is reflected below in Figure 6.

\section{CONCLUSION}

1) The theoretical and practical aspects of the construction and development of QMS, HACCP and FMEA systems are analyzed and a methodology for creating an integrated quality management system is proposed,

2) The requirements of the international standards ISO 9001: 2015 (ST RK ISO 9001: 2016), HACCP (ST RK 1179 - 2003) and FMES were studied and the degree of their compatibility was determined.

3) The requirements for an integrated quality management system based on the principles of international standards ISO 9001 series, HACCP system and FMEA model are formulated and a conceptual model of an integrated safety system and collagen production quality is proposed.

4) Areas of integration of HACCP and QMS systems were identified and an additive model for building an integrated safety and quality system was selected.

5) A network of processes has been formed for the integrated safety and quality system of baking production based on the integration of processes.

6) A model has been developed for an integrated collagen safety and quality system that meets the requirements of three standards: ST RK ISO 9001: 2016, ST RK 1179 - 2003 (HACCP system) and FMEA

\section{REFERENCES}

[1] Gafforova, E.B. et al.(2014).Technical Regulation of the Customs Union 021/2011 "On the safety of food products" [Electronic resource]. - Access mode: http://docs.cntd.ru. 2. Management in the food industry: a training manual / - M.: Publishing House "Academy of Natural Sciences", 2011. - 195 p. Food Losses and Food Waste in the Context of Sustainable Food Systems Report of the High Level Panel of Experts on Food Security and Nutrition June 2014 http://www.fao.org/3/a-i3901r.pdf

[2] Sultanova, B.K.(2009). The Customs Union of Belarus, Kazakhstan and Russia: state, problems, prospects: monograph / Under the general. ed. Almaty: KISI under the President of the Republic of 
International Journal of Engineering Research and Technology. ISSN 0974-3154, Volume 13, Number 11 (2020), pp. 3675-3684

(C) International Research Publication House. https://dx.doi.org/10.37624/IJERT/13.11.2020.3675-3684

Kazakhstan, 368 p.

[3] Savina, V.O.(2009). Features of integration of management systems / V.O. Savina // Methods of quality management. No. 12. - S. 20-25.

[4] Tungyshbaeva, U.O. (2019).Development of a model of an integrated security system and quality of bakery products: Thesis for the academic degree PhD Ph.D. 10 s

[5] Vayskrobova, E.S.(2011). Development of an integrated quality and safety management system for smoked sausages: The dissertation for the degree of candidate of technical sciences. $7 \mathrm{~s}$

[6] Smagina M.N. (2006).Management system processes. Tambov: TSTU. 100 p.

[7] Martsinkovsky D.A., Vladimirtrans A.V., Martsinkovsky O.A. (2008). Guide to the integration of management systems. Certification Association "Russian Register". - St. Petersburg: Berest. 122 s. 